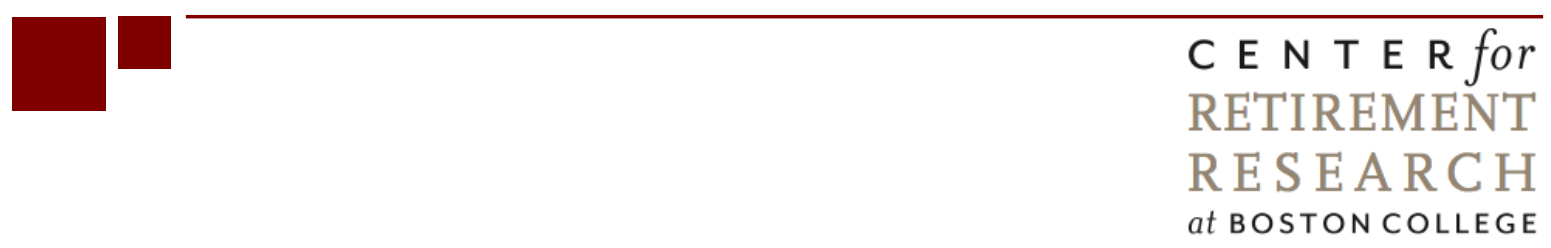

\title{
JOB DEMAND AND EARLY RETIREMENT
}

\author{
Sepideh Modrek and Mark R. Cullen
}

CRR WP 2012-19

Submitted: July 2012

Released: August 2012

\author{
Center for Retirement Research at Boston College \\ Hovey House \\ 140 Commonwealth Avenue \\ Chestnut Hill, MA 02467 \\ Tel: 617-552-1762 Fax: 617-552-0191 \\ http://crr.bc.edu
}

Sepideh Modrek is a social science research associate at the Stanford School of Medicine. Mark R. Cullen is a professor of medicine at the Stanford School of Medicine. The research reported here was performed pursuant to a grant from the U.S. Social Security Administration (SSA) funded as part of the Retirement Research Consortium (RRC). The opinions and conclusion expressed are solely those of the authors and do not represent the opinions or policy of SSA, any agency of the federal government, the RRC, the Stanford School of Medicine, or Boston College.

(C) 2012, by Sepideh Modrek and Mark R. Cullen. All rights reserved. Short sections of text, not to exceed two paragraphs, may be quoted without explicit permission provided that full credit, including (C) notice, is given to the source. 


\begin{abstract}
About the Steven H. Sandell Grant Program
This paper received funding from the Steven H. Sandell Grant Program for Junior Scholars in Retirement Research. Established in 1999, the Sandell program's purpose is to promote research on retirement issues by scholars in a wide variety of disciplines, including actuarial science, demography, economics, finance, gerontology, political science, psychology, public administration, public policy, sociology, social work, and statistics. The program is funded through a grant from the Social Security Administration (SSA). For more information on the Sandell program, please visit our website at: http://crr.bc.edu/about-us/grant-programs/steven-hsandell-grant-program-2/ send e-mail to crr@bc.edu, or call Marina Tsiknis at (617) 552-1092.
\end{abstract}

\title{
About the Center for Retirement Research
}

The Center for Retirement Research at Boston College, part of a consortium that includes parallel centers at the University of Michigan and the National Bureau of Economic Research, was established in 1998 through a grant from the Social Security Administration. The Center's mission is to produce first-class research and forge a strong link between the academic community and decision-makers in the public and private sectors around an issue of critical importance to the nation's future. To achieve this mission, the Center sponsors a wide variety of research projects, transmits new findings to a broad audience, trains new scholars, and broadens access to valuable data sources.

\author{
Center for Retirement Research at Boston College \\ Hovey House \\ 140 Commonwealth Avenue \\ Chestnut Hill, MA 02467 \\ phone: 617-552-1762 fax: 617-552-0191 \\ e-mail: crr@bc.edu \\ crr.bc.edu
}

Affiliated Institutions:

The Brookings Institution

Massachusetts Institute of Technology

Syracuse University

Urban Institute 


\begin{abstract}
Policy initiatives such as increases in the full retirement age implicitly reduce benefits for early retirement. Yet research suggests that those in physically demanding jobs may be particularly adversely affected by such policies. We examine to what extent physical job demand relates to early retirement decisions in a population of aging manufacturing workers. We follow a cohort of approximately 1,500 stably employed male Alcoa employees aged 51-58 in 2001 followed forward to 2008. We use a variety of models to examine whether externally rated physical job demand at middle age is related to early retirement. We also examine whether pension eligibility and payouts induce earlier retirement, especially for those with more physically demanding jobs, while accounting for wage differentials, injury history, and underlying health. Our results suggest that workers whose jobs have high physical demand retire earlier after accounting for the wage differential and health. We also find that the minority of workers who transition to lower demand jobs, due to previous injury or health issues, are less likely to retire early. Finally, while we find evidence that pension eligibility and wealth accumulation induce earlier retirement, there was limited evidence of a difference by job demand.
\end{abstract}




\section{Purpose}

Recent policy initiatives to address the long-term national deficit have suggested that further increases in the full retirement age (FRA) may be necessary. Yet, there are subpopulations that may be adversely affected by such changes. We explore one such population, those in physically demanding jobs. We examine whether physical job demand relates to early retirement decision while considering underlying health, injury history, and wealth accumulation in a population of aging manufacturing workers. We use a rich set of administrative data including detailed personnel records, external ratings physical job demand, injury history, health, pension, and wage data for a cohort of approximately 1,500 male Alcoa employees born between 1941-1948 followed forward from 2001 to 2008 to explore the relationship between early retirement and job demand.

\section{Aims}

1. Determine whether job demand predicts earlier retirement once we account for health and wealth.

2. Explore whether a downward progression of physical job demand delays retirement while controlling for injury history and other health considerations. ${ }^{1}$

3. Examine whether the timing of pension eligibility, which is determined by tenure and age, is more important in inducing retirement for those with more physically demanding jobs. $^{2}$

4. Examine whether pension payouts or wealth accumulation induces retirement differentially for those with more physically demanding jobs.

\footnotetext{
${ }^{1}$ Unfortunately very few members of the cohort transitioned to lower demand jobs. Those who did were found to have had a history of reportable injury or short-term disability, thus we could not build a propensity score model to compare the trajectories of "transitioners" as we had initially intended to do.

${ }^{2}$ We had intended to use difference-in-difference methods exploiting the exogenous variation created by the 1983 Social Security reform, which increased the FRA from 65 to 66 in two month increments per year of birth for cohorts born from 1938 to 1943, to examine if changes to FRA had any effect on retirement age for those with more physically demanding jobs. However, most members of this cohort retired well before reaching FRA, therefore we could not examine the effects of the 1983 Social Security reform.
} 


\section{Background}

While there have been many studies on how physically demanding jobs affect the retirement decision, they have had mixed results. Several earlier studies indicated that physical demand did relate to early retirement (either through disability or normal exit from the labor force), however these studies were based on data from the 1960's to the early 1980's (Hayward et al., 1989, Hayward, 1986, Quinn, 1978, Gustman and Steinmeier, 1986). These older studies often used occupational-level codes to determine job demand, and thus could not account for heterogeneity within job class. As a consequence, these studies inadvertently compared workers in remarkably different work environments. For example, an engineer within a manufacturing setting may have had different physical work demands and exposures than an engineer in a university setting. Newer studies using self-reported job demand constructs have not replicated the previous findings. For example, Hurd et al. (1993) used the 1992 wave of the Health and Retirement Survey (HRS) for the 1931-1941 birth cohorts and examined whether self-reported job demand related to self-reported subjective probabilities of working to age 62 and 65 . They found no association between job characteristics and earlier retirement. The Urban Institute did a similar analysis using four waves of the HRS (examining the same birth cohorts) to explore whether self-reported job demand related to actual early retirement behavior. Using a principal components variable for job demand (based on the self-reported data) they did not find a relationship between physical job demand and earlier retirement (http://www.urban.org/UploadedPDF/410609_ModelingIncome.pdf). Differences in the results of the older studies relative to the newer ones may be due to the different biases in each measure of physical job demand. For example while occupation-level codes may not capture the variation of physical job demand across context, they are assessed on a singular relative scale for all jobs. Meanwhile, self-reported job demand may capture the physical demands of a job’s context better, but may be biased because each individual respondent has his own relative scale. Ideally, externally rated job demand within similar contexts would capture the construct of interest best.

Beyond the mixed results, another distinct limitation in the literature is the population under study. Many studies have examined more educated populations such as Finish health workers (Elovainio et al., 2005), British Civil Servants (Mein et al., 2000), and high school graduates in Wisconsin (Kubicek et al., 2010). Yet, there have been fewer studies of 
construction, manufacturing, and lower level service workers. This is important because workers in these sectors have the highest physical job demands and are at the highest risk for early retirement (Blöndal and Scarpetta, 1999). Though not representative of the entire population, their experience may reflect an important portion of the job demand distribution that has been understudied.

Our study relies on an extraordinarily rich administrative data source from a large multisite aluminum-manufacturing employer, Alcoa. We use the Alcoa setting to assess whether and the extent to which physical job demand drives early retirement decisions. ${ }^{3}$ This setting provides several specific advantages over other studies. First for this population we have externally rated job demand by location, which provides us with much better data on job demand. Second, we have hourly wage data, which allows us to control for this important confounder. Since we know that there is substantial self-selection/healthy worker bias for people who hold high demand jobs because those who choose to work in high demand jobs are (Cantley et al., 2007, Clougherty et al., 2009, Cullen et al., 2010, Iennaco et al., 2010, Pollack et al., 2007)healthier and are paid more to endure the harder jobs, ${ }^{4}$ it becomes crucial to account for the marginal pay workers receive for their efforts. Third, we can examine physical demand in a sector where there are many more employees working in high demand jobs. Finally, the rich administrative data allow us to account for details on retirement age, health, and wealth; thus our work would serve as an important complement to studies done with the HRS.

\section{Methods}

Data. For this Alcoa population, we have access to personnel, physical job demand, pension, health, and wage data. The personnel data set has detailed records for each employee with records for each job change starting in 1985. This data set includes basic demographic variables (sex, race,

\footnotetext{
${ }^{3}$ In previous studies of Alcoa workers numerous investigators have linked high-quality databases containing sociodemographic data, personal health characteristics, health claims experience, mortality status and cause, physical and chemical job exposures as well as and psycho-social exposures, and plant level characteristics for some 60,000+ hourly employees (Cantley et al., 2007, Clougherty et al., 2009, Iennaco et al., 2010, Pollack et al., 2007, Busch et al., 2006)

${ }^{4}$ The theory of compensating differentials posits a positive relation between the wage rate and the unpleasantness, risk, or other undesirable attributes of a particular job (Duncan and Holmlund, 1983).
} 
year of birth), job category (hourly or salary), job title (linked to physical job demand), plant information (location and union status), employment status (active), date of entry or leave, and date of disability leave. The job demand survey data includes externally rated measures of physical and psychosocial work for the bulk of hourly Alcoa workers. A single expert rater at each plant rated the job demand by department and determined the job demand score. The raters were safety and health mangers who received training on the criteria to rate each job prior to the data collection. The physical demand required for each job was classified as sedentary/light, medium, heavy/very heavy (Cantley et al., 2007). While the survey was done in 2003, the standardized titles allow us to assign workers job demand scores going both forward and back in time because the nature of work of hourly has not changed drastically. We only match job titles going back to 1996 (because our cohort is selected in 1996). While there was some movement across job titles in these older employees there was little movement across physical job demand. About $8 \%$ of the sample does move to lower demand jobs, but $80 \%$ of these workers who transition to a lower demand job either had a short-term disability leave or a reportable injury between 1996-2006, suggesting that these transitions represent job modifications after an incident rather than a worker-initiated or employer-initiated transition. Thus in all models we include a control variable to account for this group of workers.

Beyond basic demographics and physical job demand, we can account for underlying health, injury history, pension eligibility and wealth accumulations. We have health claims data for all medical encounters beginning in 1996. We use a third-party algorithm to create a healthrisk stratification score for each individual. This algorithm is based on a chronic disease model and inputs current procedural technology codes, diagnostic codes, number of eligible months, and overall outpatient health expenditures derived from the claims data and outputs a continuous risk score (Verisk Health Inc, DxCG ${ }^{\circledR}$ Software). A score of 1 indicates that the individual is predicted to have the median health expenditure in the following year. Each unit increase indicates a one-fold increase over the median. For example, a score of 3 indicates that the individual's expected health spend will be three fold over the median the following year. We use the 1998, 1999 and 2000 lagged risk score and categorize them into quintiles to account for underlying health. We also construct an indicator variable for any employee that has had a reportable injury in the two years prior to retirement. In addition, we use pension eligibility rules 
to designate workers as pension eligible, and we estimate their respective benefit payouts based on the workers' job grade and years of service. We calculate the monthly pension benefit for each worker in each year on the worker's birthday and use inflation adjusted pension factors. ${ }^{5}$ Finally, we have detailed information on 401K accumulations starting in 2003.

We follow a cohort of male employees born between 1941-1949 working on Jan 1, 1996 ( $\mathrm{N}=3215)$, who retired after age 58 (to avoid including mainly disability related retirement and to compare like aged individuals in the time varying analysis $\mathrm{N}=2301$ ), and who retire after 1/1/2001 ( $\mathrm{N}=2243)$ forward from 1996 to the present using these merged datasets. Data considerations, such as missing data on the reason for leaving Alcoa, match rates on job titles (see appendix 1 below), and other data consideration left us with an initial analytical sample of 1791 observations. When we further account for censoring in the data (see appendix 2) and where we had no measure of underlying health, we lose observations. Thus, the sample size varies across the analyses presented below.

Statistical Analyses. Our analyses examine male, hourly employees, working at 9 different plants who retire after their $58^{\text {th }}$ birthday. This exclusion based on age 58 is to ensure that we are capturing more occurrences of normal retirement rather than disability related retirement events. We model the data using a series of logistic and Cox proportional hazard regressions.

In order to include the largest sample of the data, we begin by estimating a simple logistic regression on whether or not an employee retires past age 62. We estimate

(1) Logit (Pr of Retiring post 62) $=\alpha+\beta($ Job Demand $)+\lambda \mathbf{X}+v$ (plant) $+\gamma$ (birth cohort) $+\eta($ tenure $)$ $+\varepsilon$

In this series of models, we include controls for plant (to account for the rater), birth cohort (to account for age at a given time) and tenure groupings. We then step-in a series of control variables, $\mathbf{X}$, including race, transitioning to lower job demand, wage, marital status, health, and

\footnotetext{
${ }^{5}$ We had wanted to use the union renegotiations as a source of exogenous in the pension amounts paid, but after accounting for inflation there was very limited variation.
} 
injury history. We report odds ratios (OR) and 95\% confidence intervals. Standard errors are corrected for heteroskedasticity using Huber-White robust standard errors.

Next, since we have actual retirement dates, we employ survival analysis techniques to compare retirement curves for those in high or low demand jobs relative to medium demand jobs. After examining these descriptive patterns, we use Cox proportional hazard models to estimate the years to retirement contingent upon reaching age 58. The Cox proportional hazard equations is

(2) $h(t)=h 0(t) \exp (\alpha+\beta($ Job Demand $)+\lambda X+v($ plant $)+\gamma($ birth cohort $)+\eta($ tenure $)+\varepsilon)$

where $\mathrm{h} 0$ is the baseline hazard, $\mathrm{X}$ is a vector of covariates, and $\lambda$ is a vector of regression coefficients estimated using maximum likelihood procedures as implemented in Stata (StataCorp, 11). Here again we control for plant, birth cohort and tenure groupings in all models. In the first set of models we do not include any time varying variable. In the next set of Cox regression models, we split each observation period into one-year intervals on the birthday of each worker and add two time varying variables, pension benefits and hospitalization, to the covariate list. In the final set of Cox models, we limit the sample to workers who either had pension eligibility or participated in a $401 \mathrm{~K}$ plan and examine whether the risk of retirement is differentially related to the monthly payout of pensions or the annuitized monthly value of $401 \mathrm{~K}$ accumulations. We report hazards ratios (HR) and 95\% confidence intervals throughout.

\section{Results}

Table 1 presents the summary statistics for the male sample. All members of the sample must be at least 58 years old, born between 1941-1948, working on Jan 1, 1996, retire after 1/1/2001 and have had a matched physical job demand over the study period. Given these selection criteria, $48 \%$ of the sample retires after reaching age 62 , and the median age of retirement is 61.7 years old (less than 3\% of the sample workers continue to work at Alcoa until reaching the FRA). Approximately $30 \%$ of the employees worked in jobs categorized as 'heavy' or 'very heavy' job demand and $17 \%$ worked in jobs categorized as 'sedentary or light' job demand. Over the course of the study about $8 \%$ of the cohort transitions to a lower demand job, and $8 \%$ had at least one reportable injury over in the two-year period prior to retirement. The average median hourly wage for the employees is $\$ 18.47$, and the average tenure at Alcoa is 30 
years. About $90 \%$ of them have been married, and $89 \%$ are white.

For each member of the cohort, we defined an indicator variable set to 1 if he retired after reaching age 62. This allowed us to use the maximum number of matched observation in the analysis. We then estimated a logistic regression model of the probability of retiring after 62 . The estimated odds ratios and 95\% confidence intervals are presented in Table 2. The base model in column 1 includes birth cohort fixed effects, tenure groupings fixed effects, plant location fixed effects, the employee's race and whether the employee transitioned to a lower demand job. To examine the impact of controlling for wages, marital status, health and injury history each subsequent column (columns 2-5) adds these variables to the model one at a time. In the base model, job demand is not related to retiring after age 62. Once we add wage to the model, the odds ratio of having a high demand job decrease (OR= 0.79; 95\% CI 0.59 - 1.06), suggesting that those with higher demand jobs are less likely to retire after age 62 (i.e. they retire earlier), but the magnitude of the odds ratio is not statistically significant. In column 4 after adding marital status and lagged health to the model, the magnitude of estimated odds ratio is little changed but becomes marginally statistically significant (OR=0.77; 95\% CI 0.57-1.05). Other variables that increase the probability of retirement after age 62 across the models/columns were final wages (a $1 \$$ increase in final wage increases the odds of retiring after age $62, \mathrm{OR}=1.6$; 95\% CI 1.4-1.8), and having ever been married ( $\mathrm{OR}=1.4$; 95\% CI 0.98-2.1). The probability of retirement after age 62 is decreased for employees in the worst health quintile (OR=0.66; 95\% CI 0.45-0.96), and for employees who have a reportable injury in the two years prior to retirement $(\mathrm{OR}=0.41$; 95\% CI 0.27-0.62).

For much of the cohort we had details on the actual date of retirement. We use this information to model the retirement outcome in a survival model context. Figure 1 presents the Kaplan-Meier survival curves of time to retirement after age 58 for the sample. At time=0, all members of the cohort must be 58 years old and each time period interval is equivalent to one year. The top panel of Figure 1 shows that most of the workers retire well before reaching FRA and over half retire before reaching age 62. The median age of retirement is 61.70 , and there is a striking 
decline in the survival curve at time $=4$ or at age $62 .{ }^{6}$ Alcoa's normal pension eligibility requires either 5 years of service \& reaching age 65, 10 years of service and reaching the age 62, or 30 years of services, so this dramatic decline at 62 is not surprising. ${ }^{7}$ The bottom panel in Figure 1 shows the survival curves by the 3 job demand groups. In these unadjusted curves, those with higher physically demanding jobs seem to remain working slightly longer up to age 62 .

To explore these relationships further we estimated hazard ratio and 95\% confidence intervals for the association between job demand and time to retirement using Cox proportional hazard models. The results are presented in Table 3. The first specification in column 1 includes birth cohort fixed effects, tenure groupings fixed effects, plant location fixed effects, the employee's race and whether the employee had an injury in the last two years. In this base model we find that the estimated coefficient for workers with highly physically demanding jobs is estimated to be less than 1 (though insignificant) suggesting that employees in the most physically demanding jobs work longer than those in the medium jobs. However, once we account for final hourly wages (a measure that should account for compensating differentials) in column 2, the coefficient changes directions and is greater than 1 though statistically insignificant. Once we account for those who transition in to lower demand jobs, marital status and underlying health, the estimated hazard ratios on the job demand variable order monotonically; those in the lowest demand jobs are estimated to delay retirement relative to those in the medium demand ( $\mathrm{HR}=0.84$; 95\% CI 0.70-1.00), and those in high demand jobs retire at younger ages relative to the medium demand group ( $\mathrm{HR}=1.17 ; 95 \% \mathrm{CI}=0.99$ - 1.39). In column 5, we also find that those with higher health risk scores are more likely to retire early.

\footnotetext{
${ }^{6}$ There is a also eligibility for those that have 10 years of service and are 60 years old but the benefits are reduced. We do not consider these individuals as eligible because we do not know the rules for the reduced benefits.

${ }^{7}$ To explore the economic consequences of retiring at age 62, we calculated the income levels after retirement. Taking the three sources of income that we know of in this population (defined benefits pension payouts, $401 \mathrm{~K}$ accumulations, and estimated SS monthly benefits at age 62), we can calculate retirement ratios for the workers in our cohort. We then compare the calculated retirement ratios with retirement ratios required to maintain one's standard of living post-retirement. Incomes required to maintain a the same standard of living after retirement are lower because income taxes go down after retirement, social security taxes end at retirement, social security benefits are (mostly) tax-exempt, saving for retirement ( $401 \mathrm{~K}$ defined contributions or monthly payments to pension options) are no longer needed. Required retirement replacement ratios, gross income after retirement divided by gross income before retirement, were calculated for different income levels in a report by Aon consulting. The report shows that the required replacement ratios for individuals making $\$ 30,000-\$ 40,000$ was about $90 \%$, for individuals making $\$ 40,000-\$ 50,000$ it was about $85 \%$, and for individuals making $\$ 50,000-\$ 60,000$ it was about $81 \%$ of preretirement incomes. Most workers in our cohort earn retirement ratios close to the required proportions suggested by the report. However, those with the highest job demand (and often the highest before retirement income) fall a bit shorter because their pre-retirement income was higher.
} 
In Table 4 we take advantage of the time varying information in the data and present our results using time-varying Cox methods. Here we divide each observation into one-year intervals defined by each workers birthday. Whether the employee is hospitalized and whether he is eligible for pension benefits are then determined over that time window. All the models include controls for final wage, injury history, race, health risk score in 2000, transition to a lower demand job, and having ever been married. Focusing on column 4, we find that the estimated hazard ratios on the job demand variable order monotonically again. We find that workers in low demand jobs retire later $(\mathrm{H}=0.81$; 95\% CI 0.68-0.99), and that employees with high demand jobs retire earlier (HR=1.16; 95\% CI 0.97-1.37), but the coefficient on the latter association is only marginally statistically significant. We also find that eligibility for the defined benefit pension is strongly associated with earlier age of retirement (HR=1.55; 95\% CI 1.18-2.03). In contrast, participation in the $401 \mathrm{~K}$ defined contribution pension scheme was associated with later retirement (HR=0.71; 95\% CI 0.59-0.86). We also find that hospitalization was associated with a HR greater than 1, but the association is not statistically significant across models.

In columns $5 \& 6$ of Table 4 we further examine whether pension eligibility or $401 \mathrm{~K}$ participation affects those with higher or lower physical job demand differentially. In column 5 we find that the there is no significant difference in retirement age for eligible workers with low or high job demand relative to the medium job demand. In contrast in column 6 , we do find a statistically significant difference by job demand for the association between retirement and $401 \mathrm{~K}$ participation. Here we must be careful in interpreting the coefficients on the interactions because we must account for the movement in the main coefficient on $401 \mathrm{~K}$ participation and job demand variables. We compute the overall coefficient and compare workers in high demand jobs who participate in the $401 \mathrm{~K}$ plan relative to workers in the medium demand job who participate in the 401 program, and we find a significant and elevated hazard ratio of 1.21 (95\% CI 1.01-1.46). Comparing the overall coefficient for workers in low demand jobs who participate in the $401 \mathrm{~K}$ program relative to workers in the medium demand job who participate in the $401 \mathrm{~K}$ program, we do not find a statistically significant difference in the overall hazard ratio $(\mathrm{HR}=0.91 ; 95 \% \mathrm{CI} \quad$ 0.75-1.11).

For those who are eligible for a defined benefit pension or those who participate in the defined contributions $401 \mathrm{~K}$ program, we further explore if the dollar amount of these 
benefits/assets are related to the retirement decision, and if so, do the associations vary by job demand. For each defined benefit eligible employee, we use inflation adjusted pension factors (in 2001 dollars) to calculate their monthly pension payouts based on a matrix provided by the company. Monthly pension payouts vary by job grade, years of service and timing of retirement. Figure 2 provides a schematic of the monthly pensions for those in a specific job grade over time. Though initially we noted that the pension factors varied substantially by the year that the employee retired (Figure 2; Panel A), we found that the pension factors were very similar after adjusting for inflation (Figure 2; Panel B). ${ }^{8}$ For the $401 \mathrm{~K}$ accumulations, we take the accumulations that the employee had in $2003,{ }^{9}$ and annuitize them. We assume a $3 \%$ interest rate and 25 years of remaining life and calculate the monthly payout of the $2003401 \mathrm{~K}$ accumulations. ${ }^{10}$

To explore 'the pull' of monthly pension payouts and annuitized monthly 401K wealth accumulation on retirement, we again use the time-vary Cox proportional hazard models. These results are presented in Table 5. In columns $2 \& 3$ we present the results for employees who are eligible for the defined benefits pension plan, and in columns $4 \& 5$ we present results for employees who participate in the defined contribution 401k plan. For both measures of retirement assets, we find that having more assets/getting a higher payout leads to an earlier retirement. The estimated coefficient suggests that a $100 \$$ increase in the defined benefits pension payouts leads to a 50\% increase in the hazard of retirement ( $\mathrm{HR}=1.5$; 95\% CI 1.4-1.6), while a $100 \$$ increase in the monthly annuitized $401 \mathrm{~K}$ accumulations was associated with a $4 \%$ increase in the hazard of retirement ( $\mathrm{HR}=1.04 ; 95 \%$ CI 1.01-1.06). When we interact the defined benefit pension payouts by job demand, we do not find evidence of a differential behavior by physical job demand. Likewise, when we interact the 401K annuitized amounts with physical job demand, we do not find a relationship by job demands. Of course while the defined benefit does not increase if deferred the value of the $401 \mathrm{k}$, viewed as an annuity, does.

\footnotetext{
${ }^{8}$ We had wanted to use the timing of retirement as a source of exogenous in the pension amounts paid, but after accounting for inflation there was very limited variation.

${ }^{9} 2003$ is the first year for which we have the total accumulations. We assign these total back in time to 2001 in order not to lose members of the cohort.

${ }^{10}$ Life expectancy for men in the social security population was 22.48 years according to the 2007 Period life tables found at www.ssa.gov/oact/STATS/table4c6.html. We round to 25 years.
} 


\section{Discussion}

Our analysis suggests that those in the most physically demanding jobs retire earlier once you account for wage differentials and health, though this finding is only marginally significant in most models. We also find that the minority of workers who transition into a less physically demanding job are less likely to retire early, though these workers were likely to have transitioned after an injury or after returning from short-term disability leave. We also find that that recent injury history is associated with earlier retirement. Finally, while we find evidence of a strong 'pull' effect of pension eligibility, pension payouts and 401K wealth accumulation, there is limited evidence of a difference by job demand, though we find that those in high job demand who participate in the $401 \mathrm{~K}$ scheme retire earlier.

Our results are interesting in comparison to the previous studies done with the Health and Retirement Survey where physical job demand was not found to be related to early retirement. Though the HRS has a much larger population that is nationally representative, the physical demand measure it uses is a self-reported job demand question, "Does your job require lots of physical effort (none/some/most/all/) of the time.” Individuals who report high job demand may not have a good external reference point upon which to compare their physical exertion at work. In our study jobs were rated for physical demand by an external rater with a single frame for relative comparisons. This may explain some of the difference between studies, and we think our measurements are more ideal. Moreover, our sample includes a sector with more physically demanding jobs. According to HRS 22\% of men aged 51-61 report having a job that requires lots of physical effort all of the time, ${ }^{11}$ relative to the $30 \%$ we have in our sample. This could further explain the difference in results.

We also find that injury history relates to earlier retirement. Injuries that limit physical function would naturally lead employees to seek disability benefits (such as disability retirement benefits which are offered by Alcoa), or early retirement option. In our study we find that employees with a history of a reportable injury in the two years prior to retirement are more likely to retire at younger ages. Indeed a recent study found that having a lost-time injury substantially increase

11 Due to the lack of external reference point we expect that this $21 \%$ may be an overestimate. 
the probability of SSDI receipt (O'Leary et al., 2012). In our sample we are not able to differentiate earlier retirement from disability retirement. We do however differentiate workers who have transitioned to lower demand jobs, and we found that those who transition to lower demand jobs remain working longer. However, we do not interpret this result as causal. Over $80 \%$ of these "transitioners" had a reportable injury early on or came back from short term disability during our study period. While we found that these "transitioners" delayed retirement, these may be workers who chose to remain in the workforce and transitioned to facilitate that rather than the other way around. Our data does not allow us to fully understand these relationships, because we only know who selected to continue working in a lower demand job and not necessarily who was offered this option. We have explored the possibility of using an instrument to explore the causal direction, such as 'tenure' (the chief determinant of opportunity to transfer jobs in these union plants) or 'location' (since the locations differ in such opportunities as well). Unfortunately both of these variables are associated with the outcome through other pathways as well and are already controlled for in the analysis

There are several other limitations in this study that merit attention. First in an effort to limit the retirement events related to disability, we focus on a narrow age range, men aged 58+. In order to look at a broader age range we would need to distinguish the disability population from the early retirement population. Second, the retirement choices of Alcoa employees may not be generalized to the US population. Though we recognize this limitation, our sample does provide better estimates for the relationship between physical job demand and retirement for some groups of workers. Specifically our results may be germane to those working in mining, manufacturing, and construction related occupations. Finally, though we have education data on most employees, there is some missing data, and, more importantly, too little observed variation; most are high school graduates. Previous studies that include education find that it is the most robust predictor of male labor force participation ((Blau and Goldstein, 2007), and education is likely to be negatively correlated to physical job demand. This leaves open the question of whether our results are capturing the effects of education or job demand on retirement. Finally, our results show that the statistical significance of the relationship between physical job demand and retirement age is somewhat sensitive to specification and sample selection, so we must be careful not to over interpret the results. Notwithstanding these real limitations, our data provided 
us the distinct advantage to examine physical job demand in more detail than previously done, and allowed us to examine retirement behavior while accounting for health, job characteristics and personal economic factors.

Future work will build on these mostly descriptive analyses and attempt to further clarify the relationship found in this study. We envision two distinct directions: (1) understanding the relationship between disability retirement and job demand in a younger cohort of workers, and (2) modifying and developing structural models of retirement (such as (Gustman and Steinmeier, 2002)) and incorporating information on time preferences and risk aversion, which we can estimate for the employees based on other decision dimensions (i.e. choice of health care benefits (Finkelstein et al., 2012)). Such a model would allow inclusion of factors omitted here, such as the role health care costs may play in retirement timing, and to directly assess the inter-individual variation in "disutility for labor" conditional on age, health and wealth status exploiting the unparalleled richness of our administrative data. In addition, we have recently incorporated linked CMS files for this cohort, allowing us to explore health in the post-retirement period (“year 66") for almost all, potentially revealing previously unobserved health factors which may have predisposed some to earlier rather than later retirement choice. 


\section{List of Publications and Products}

1. Presentation at Population Association of America

2. Manuscript summarized in this report

3. Future work and grants 


\title{
Appendix 1: Mapping Rating of Physical Job Demand
}

\author{
Job Demand Survey and Physical Job Demand
}

Objective ratings of physical job demands were obtained using a job demand survey conducted by a safety and hygiene manager who was familiar with each job and department in each of 11 plant locations. We only include the 9 union plants for which we have work demand survey. Ratings were available for all job titles in each location in 2003. A single safety and hygiene manager at each location received training on the criteria to rate each job and rated the complete list of job titles by department (ranging from 24 to 81 jobs per location). These ratings served as the main the physical demand rating and each job was classified as sedentary, light, medium, heavy, or very heavy. While the survey was done in 2003, the standardized titles were used to assign workers job demand scores going both forward and back in time as the nature of work of hourly has not changed drastically. The algorithm for the assignment is detailed below.

\section{Algorithm for matching}

For all workers in our final cohort we extracted their job titles, departments, and work locations during the study period from the human resources files (after 1.1.1996). After cleaning the titles for extraneous characters, we first merged the job titles, departments, and work locations directly to the job demand survey (541 matched job titles). We then matched all the same job titles by location regardless of department (leading to an additional 324 matched job titles). Since there were many iterations of titles in the human resources files, we used a Levenshtein edit distance algorithm to map similar titles within locations (using the strgroup function in Stata with a cutoff of 0.3$){ }^{12}$ This produced 935 job title groupings which were examined for further potential groupings by comparing job titles and collapsing job titles that were the same or very similar, but not recognized by the edit distance algorithm. (Example CONT_COLD_MILL_OPERATOR was grouped with CONTINUOUS_MILL_OPR). After collapsing job titles, about 800 unique groups remained.

Based on these groupings, job titles were assigned a physical demand. If there was a perfect match between the job titles and the initial job demand survey then that physical demand rating was given. If the job titles were matched in a group that had a physical demand rating then the average of that group was assigned (see Appendix Table 1 for an example).

For each member of the cohort whose job mapped to the job-demand linking file (based on location department name and job title), he was assigned a job demand value using the maximum job demand in the study period. This method gave an $83 \%$ match rate.

\footnotetext{
${ }^{12}$ The code used to calculate the Levenshtein edit distance is based on a Python extension written by David Necas and it was implemented in STATA 11(StataCorp, 11).
} 
Appendix Table 1: Example of matching of Physical Job Demand

\begin{tabular}{|c|c|c|c|c|c|c|}
\hline $\begin{array}{l}\text { Match } \\
\text { Group } \\
\text { by Edit } \\
\text { Distance }\end{array}$ & Job Title & $\begin{array}{l}\text { Department } \\
\text { Name }\end{array}$ & Location & $\begin{array}{c}\text { Matched } \\
\text { in Job } \\
\text { demand } \\
\text { Survey }\end{array}$ & $\begin{array}{c}\text { Physical } \\
\text { Demand } \\
\text { Rating in } \\
\text { Job } \\
\text { demand } \\
\text { Survey } \\
\end{array}$ & $\begin{array}{c}\text { Assigned } \\
\text { Physical } \\
\text { Demand } \\
\text { Rating by } \\
\text { Match } \\
\text { Group } \\
\end{array}$ \\
\hline 142 & SLIT_PACK_UTLITY & $\begin{array}{c}\text { TN } \\
\text { FINISHING } \\
\text { PROD } \\
\text { TN }\end{array}$ & ALC & YES & 3 & 3 \\
\hline 142 & SLIT_PACK_UTILITY & $\begin{array}{c}\text { FINISHING } \\
\text { PROD } \\
\text { TN }\end{array}$ & ALC & YES & 3 & 3 \\
\hline 142 & SLIT_PACK_UTLITY & $\begin{array}{l}\text { FINISHING } \\
\text { PROD }\end{array}$ & ALC & YES & 3 & 3 \\
\hline 142 & SLIT_PACK_UTLITY & $\begin{array}{c}\text { TN } \\
\text { FINISHING } \\
\text { PROD } \\
\text { TN }\end{array}$ & ALC & YES & 3 & 3 \\
\hline 142 & SLIT_PACK_UTILITY & $\begin{array}{l}\text { FINISHING } \\
\text { PROD }\end{array}$ & ALC & YES & 3 & 3 \\
\hline 142 & SLIT_PACK_UTL & & ALC & NO & & 3 \\
\hline 142 & SLIT_PACK_UTLITY & $\begin{array}{c}\text { TN N } \\
\text { TRANSPORT } \\
\end{array}$ & ALC & YES & 3 & 3 \\
\hline
\end{tabular}




\section{Appendix 2: Censoring of the data}

Age structure and observation window

We try to balance capturing the most number of observations with the concern of capturing workers at the appropriate ages. In the table below we outline the ages of the members of the cohort and compare median retirement ages to ensure that because our observation window is limited we do not include very different populations. For example if we include the 1940 birth cohort we would be including members who are aged 60 and over at the beginning of the observation window. This is likely to skew the age at retirement because it will be conditional on having reached 60 (instead of 58). Likewise if we include the 1949 cohort that will just reach age 58 at the end of the observation period and therefore we do not observe many retirement events. For these data reasons we only include the 1941-1948 birth cohorts and only allow observations to contribute person-time after reaching age 58.

Appendix Table 2: Median Retirement Age by birth cohort

\begin{tabular}{|ccccc|}
$\begin{array}{c}\text { Birth } \\
\text { Cohort }\end{array}$ & $\begin{array}{c}\text { Age in } \\
\mathbf{2 0 0 1}\end{array}$ & $\begin{array}{c}\text { Age in } \\
\mathbf{2 0 0 7}\end{array}$ & $\begin{array}{c}\text { Median age } \\
\text { at } \\
\text { retirement** }\end{array}$ & $\begin{array}{c}\text { Prop. } \\
\text { Retirement } \\
\text { Verified }\end{array}$ \\
\hline 1940 & $60-61$ & $66-67$ & 62.04 & $84 \%$ \\
1941 & $59-60$ & $65-66$ & 61.77 & $88 \%$ \\
1942 & $58-59$ & $64-65$ & 61.32 & $83 \%$ \\
1943 & $57-58$ & $63-64$ & 61.6 & $82 \%$ \\
1944 & $56-57$ & $62-63$ & 61.52 & $81 \%$ \\
1945 & $55-56$ & $61-62$ & 61.36 & $59 \%$ \\
1946 & $54-55$ & $60-61$ & 61.62 & $36 \%$ \\
1947 & $53-54$ & $59-60$ & 61.89 & $16 \%$ \\
1948 & $52-53$ & $58-59$ & 60.91 & $12 \%$ \\
1949 & $51-52$ & $57-58$ & 59.99 & $6 \%$ \\
\hline
\end{tabular}


Figure 1: Survival curves by job demand.
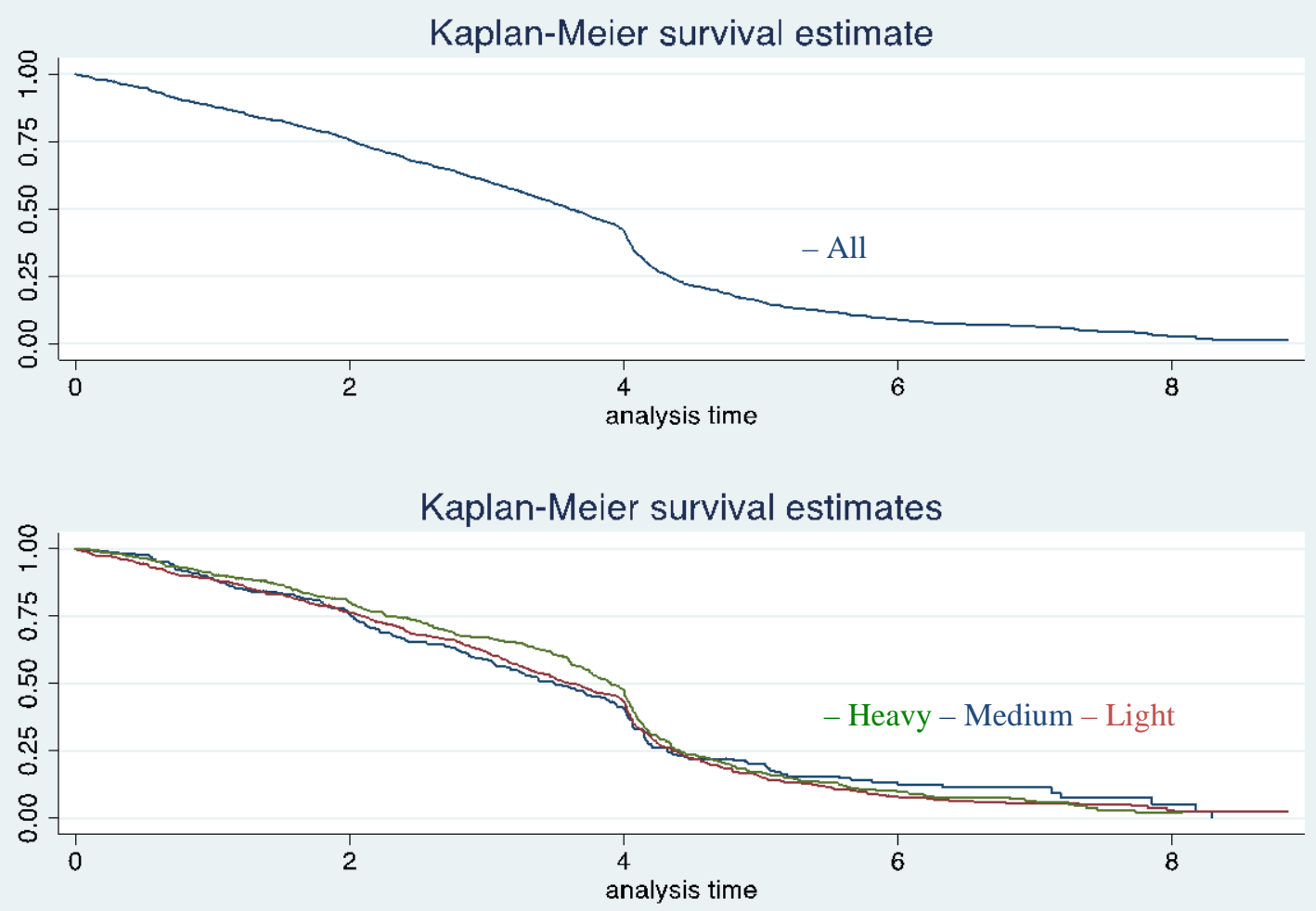

Analysis time $=0$ is at age 58 and data is right censored at $1 / 1 / 2001$. For those without a retirement date data is left censored at 1/1/2008. 
Figure 2: Stylized pension amounts for employees in job grade 13-16.

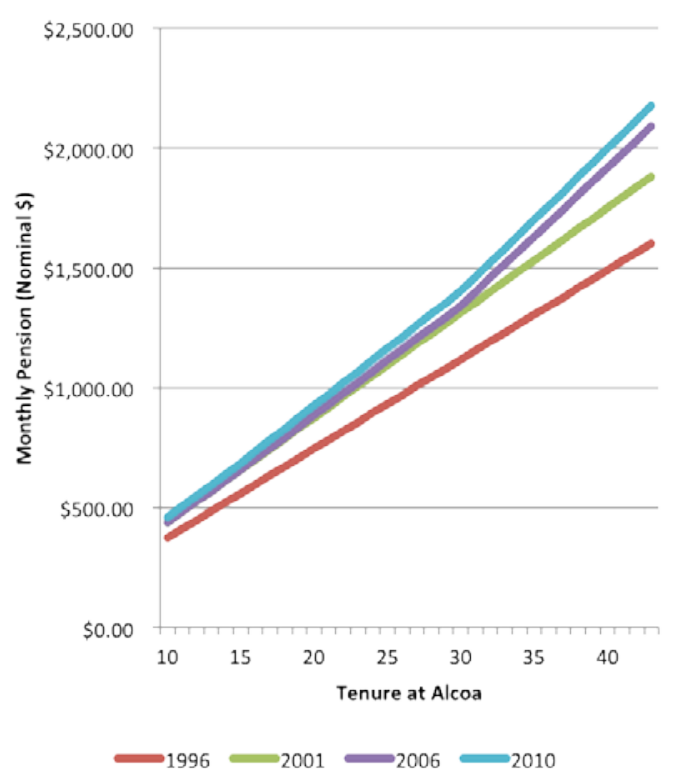

Panel A: Pension Factors in Nominal \$

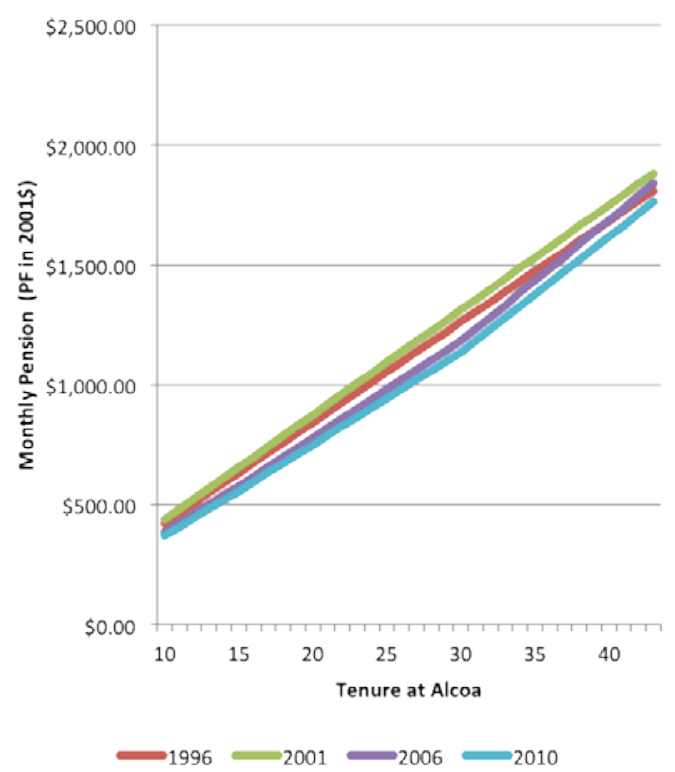

Panel B: Pension Factors Adjusted to 2001 \$ 
Table 1: Summary Statistics

\begin{tabular}{|c|c|c|c|c|}
\hline & \multicolumn{2}{|c|}{ Logistic Sample } & \multicolumn{2}{|c|}{ Cox Sample } \\
\hline & Mean/Percent & $\mathrm{SD}$ & Mean/Percent & $\mathrm{SD}$ \\
\hline $\begin{array}{c}\text { Retire after } \\
\text { age } 62\end{array}$ & $48 \%$ & & & \\
\hline $\begin{array}{l}\text { Age at } \\
\text { retirement } \\
\text { Wage }\end{array}$ & & & 61.48 & 1.71 \\
\hline $\begin{array}{c}\text { Final Hourly } \\
\text { Wage }\end{array}$ & 18.47 & 2.00 & 18.37 & 1.97 \\
\hline$\underline{\text { Job Demand }}$ & & & & \\
\hline $\begin{array}{l}\text { Sedentary/ } \\
\text { Light }\end{array}$ & $17 \%$ & & $17 \%$ & \\
\hline Medium & $53 \%$ & & $53 \%$ & \\
\hline $\begin{array}{c}\text { Heavy/Very } \\
\text { Heavy }\end{array}$ & $30 \%$ & & $30 \%$ & \\
\hline $\begin{array}{l}\text { Transition to } \\
\text { lower demand } \\
\text { job } \\
\text { Iniury }\end{array}$ & $8 \%$ & & $8 \%$ & \\
\hline $\begin{array}{l}\text { Injured within } \\
2 \text { years of } \\
\text { retirement } \\
\text { Tenure at }\end{array}$ & $8 \%$ & & $9 \%$ & \\
\hline entry & & & & \\
\hline $0-15$ years & $7 \%$ & & $5 \%$ & \\
\hline $15-20$ & $3 \%$ & & $3 \%$ & \\
\hline $20-25$ & $13 \%$ & & $13 \%$ & \\
\hline $25-30$ & $19 \%$ & & $18 \%$ & \\
\hline $30-35$ & $32 \%$ & & $33 \%$ & \\
\hline $35-40$ & $26 \%$ & & $27 \%$ & \\
\hline Married & & & & \\
\hline $\begin{array}{c}\text { Ever Married } \\
\text { Race }\end{array}$ & $90 \%$ & & $89 \%$ & \\
\hline White & $89 \%$ & & $90 \%$ & \\
\hline Health & $\mathrm{N}=1611$ & & $\mathrm{~N}=1490$ & \\
\hline $\begin{array}{c}\text { Health Score } \\
2000 \text { Q1 }\end{array}$ & $19 \%$ & & $19 \%$ & \\
\hline $\begin{array}{c}\text { Health Score } \\
2000 \text { Q2 }\end{array}$ & $21 \%$ & & $21 \%$ & \\
\hline $\begin{array}{c}\text { Health Score } \\
2000 \text { Q3 }\end{array}$ & $21 \%$ & & $21 \%$ & \\
\hline $\begin{array}{c}\text { Health Score } \\
2000 \text { Q4 }\end{array}$ & $20 \%$ & & $21 \%$ & \\
\hline
\end{tabular}




\begin{tabular}{ccc}
$\begin{array}{c}\text { Health Score } \\
2000 \mathrm{Q} 5\end{array}$ & $18 \%$ & $18 \%$ \\
\hline $\mathrm{N}$ & 1791 & 1660 \\
\hline
\end{tabular}


Table 2: Logistic Regression of the probability of retiring after age 62

\begin{tabular}{|c|c|c|c|c|c|}
\hline \multicolumn{6}{|l|}{$\begin{array}{l}\text { Logistic Regression for Working } \\
\text { Past age } 62\end{array}$} \\
\hline & (1) & (2) & (3) & (4) & (5) \\
\hline \multicolumn{6}{|l|}{$\begin{array}{l}\text { Job Demand\& (omitted JD=3, } \\
\text { Medium) }\end{array}$} \\
\hline Sedentary/Light $(\mathrm{JD}=1$ or 2$)$ & $\begin{array}{c}0.864 \\
(0.651- \\
1.145)\end{array}$ & $\begin{array}{c}1.096 \\
(0.803- \\
1.495)\end{array}$ & $\begin{array}{c}1.087 \\
(0.796- \\
1.485)\end{array}$ & $\begin{array}{c}1.013 \\
(0.726- \\
1.414)\end{array}$ & $\begin{array}{c}0.98 \\
(0.702- \\
1.370)\end{array}$ \\
\hline Heavy/Very Heavy (JD=4 or 5) & $\begin{array}{c}0.964 \\
(0.731- \\
1.272)\end{array}$ & $\begin{array}{c}0.794 \\
(0.593- \\
1.064)\end{array}$ & $\begin{array}{c}0.794 \\
(0.593- \\
1.064)\end{array}$ & $\begin{array}{c}0.774^{*} \\
(0.571 \text { - } \\
1.049)\end{array}$ & $\begin{array}{c}0.791 \\
(0.583- \\
1.073)\end{array}$ \\
\hline \multicolumn{6}{|l|}{$\begin{array}{l}\text { Changed to lower demand job } \\
\text { after 1/1/96 }\end{array}$} \\
\hline Transitioned to lower demand & $\begin{array}{c}1.971 * * * \\
(1.333- \\
2.914)\end{array}$ & $\begin{array}{c}3.013 * * * \\
(2.003- \\
4.532)\end{array}$ & $\begin{array}{c}2.982 * * * \\
(1.982- \\
4.486)\end{array}$ & $\begin{array}{c}3.095 * * * \\
(2.018- \\
4.749)\end{array}$ & $\begin{array}{c}3.107 * * * \\
(2.033- \\
4.750)\end{array}$ \\
\hline \multicolumn{6}{|l|}{ Race } \\
\hline White & $\begin{array}{c}0.877 \\
(0.627- \\
1.225)\end{array}$ & $\begin{array}{c}0.710^{*} \\
(0.499- \\
1.012)\end{array}$ & $\begin{array}{c}0.695^{* *} \\
(0.487- \\
0.991)\end{array}$ & $\begin{array}{c}0.664 * * \\
(0.455- \\
0.968)\end{array}$ & $\begin{array}{c}0.698^{*} \\
(0.476- \\
1.021)\end{array}$ \\
\hline \multicolumn{6}{|l|}{ Wage } \\
\hline Final Hourly Wage & & $\begin{array}{c}1.636^{* * *} \\
(1.428- \\
1.874)\end{array}$ & $\begin{array}{c}1.630^{* * *} \\
(1.423- \\
1.868)\end{array}$ & $\begin{array}{c}1.568^{* * *} \\
(1.357- \\
1.811)\end{array}$ & $\begin{array}{c}1.567 * * * \\
(1.356- \\
1.811)\end{array}$ \\
\hline \multicolumn{6}{|l|}{$\underline{\text { Married }}$} \\
\hline Ever Married & & & $\begin{array}{c}1.295 \\
(0.919- \\
1.825)\end{array}$ & $\begin{array}{c}1.407^{*} \\
(0.959- \\
2.063)\end{array}$ & $\begin{array}{c}1.442^{*} \\
(0.977 \text { - } \\
2.128)\end{array}$ \\
\hline \multicolumn{6}{|l|}{ Health (omitted Q1) } \\
\hline Health Score 2000 Q2 & & & & $\begin{array}{c}0.912 \\
(0.642- \\
1.296)\end{array}$ & $\begin{array}{c}0.908 \\
(0.638- \\
1.294)\end{array}$ \\
\hline Health Score 2000 Q3 & & & & $\begin{array}{c}0.909 \\
(0.639- \\
1.293)\end{array}$ & $\begin{array}{c}0.913 \\
(0.642- \\
1.300)\end{array}$ \\
\hline Health Score 2000 Q4 & & & & $\begin{array}{c}0.851 \\
(0.591- \\
1.224)\end{array}$ & $\begin{array}{c}0.881 \\
(0.611- \\
1.269)\end{array}$ \\
\hline Health Score 2000 Q5 & & & & $\begin{array}{c}0.627 * * \\
(0.431- \\
0.911)\end{array}$ & $\begin{array}{c}0.658^{* *} \\
(0.451- \\
0.959)\end{array}$ \\
\hline$\frac{\text { Reportable Injury History }}{\text { Iniury within } 2 \text { yrs of retirement }}$ & & & & & 0 \\
\hline
\end{tabular}


$(0.270-$

$0.618)$

\begin{tabular}{llllll}
\hline Observations & 1798 & 1791 & 1791 & 1611 & 1611 \\
Birth Cohort FE & YES & YES & YES & YES & YES \\
Location FE & YES & YES & YES & YES & YES \\
Tenure FE & YES & YES & YES & YES & YES \\
\hline
\end{tabular}

Robust standard errors used; ${ }^{* * *} \mathrm{p}<0.01,{ }^{* *} \mathrm{p}<0.05,{ }^{*} \mathrm{p}<0$. 
Table 3: Cox Proportional Hazard Model of years to retirement after reaching age 58

\begin{tabular}{|c|c|c|c|c|c|}
\hline \multirow{2}{*}{$\begin{array}{l}\text { Time to Retirement (after } \\
\text { 1/1/2001) }\end{array}$} & \multicolumn{5}{|c|}{ Hazard Ratio (95 \% Confidence Interval) } \\
\hline & (1) & (2) & (3) & (4) & (5) \\
\hline \multicolumn{6}{|l|}{$\begin{array}{l}\text { Job Demand\& (omitted JD=3, } \\
\text { Medium) }\end{array}$} \\
\hline Sedentary/Light (JD=1 or 2) & $\begin{array}{c}1.036 \\
(0.879- \\
1.222)\end{array}$ & $\begin{array}{c}0.87 \\
(0.732- \\
1.035)\end{array}$ & $\begin{array}{c}0.839 * * \\
(0.705- \\
0.999)\end{array}$ & $\begin{array}{c}0.840 * * \\
(0.706- \\
0.999)\end{array}$ & $\begin{array}{c}0.831 * \\
(0.689- \\
1.002)\end{array}$ \\
\hline $\begin{array}{l}\text { Heavy/Very Heavy (JD=4 or } \\
\text { 5) }\end{array}$ & $\begin{array}{c}0.975 \\
(0.824- \\
1.154)\end{array}$ & $\begin{array}{c}1.078 \\
(0.919- \\
1.264)\end{array}$ & $\begin{array}{c}1.135 \\
(0.965- \\
1.334)\end{array}$ & $\begin{array}{c}1.139 \\
(0.968- \\
1.339)\end{array}$ & $\begin{array}{c}1.174 * \\
(0.989- \\
1.392)\end{array}$ \\
\hline$\frac{\text { Race }}{\text { White }}$ & $\begin{array}{c}1.177 \\
(0.954- \\
1.453)\end{array}$ & $\begin{array}{c}1.393 * * * \\
(1.123- \\
1.728)\end{array}$ & $\begin{array}{c}1.424 * * * \\
(1.148- \\
1.767)\end{array}$ & $\begin{array}{c}1.436 * * * \\
(1.156- \\
1.785)\end{array}$ & $\begin{array}{c}1.394 * * * \\
(1.103- \\
1.762)\end{array}$ \\
\hline$\frac{\text { Wage }}{\text { Final Hourly Wage }}$ & & $\begin{array}{c}0.641 * * * \\
(0.611- \\
0.672)\end{array}$ & $\begin{array}{c}0.635 * * * \\
(0.606- \\
0.666)\end{array}$ & $\begin{array}{c}0.635 * * * \\
(0.606- \\
0.666)\end{array}$ & $\begin{array}{c}0.637 * * * \\
(0.605- \\
0.670)\end{array}$ \\
\hline \multicolumn{6}{|l|}{$\begin{array}{l}\text { Changed to lower demand job } \\
\text { after } 1 / 1 / 96\end{array}$} \\
\hline Transitioned to lower demand & & & $\begin{array}{c}0.582 * * * \\
(0.452- \\
0.749)\end{array}$ & $\begin{array}{c}0.584 * * * \\
(0.454- \\
0.753)\end{array}$ & $\begin{array}{c}0.580 * * * \\
(0.444- \\
0.757)\end{array}$ \\
\hline \multicolumn{6}{|l|}{ Married } \\
\hline Ever Married & & & & $\begin{array}{c}0.939 \\
(0.778- \\
1.134)\end{array}$ & $\begin{array}{c}0.98 \\
(0.800- \\
1.200)\end{array}$ \\
\hline \multicolumn{6}{|l|}{ Health (omitted Q1) } \\
\hline Health Score 2000 Q2 & & & & & $\begin{array}{c}1.149 \\
(0.910- \\
1.451)\end{array}$ \\
\hline Health Score 2000 Q3 & & & & & $\begin{array}{c}1.325^{* *} \\
(1.048- \\
1.676)\end{array}$ \\
\hline Health Score 2000 Q4 & & & & & $\begin{array}{c}1.209 \\
(0.957- \\
1.529)\end{array}$ \\
\hline Health Score 2000 Q5 & & & & & $\begin{array}{c}1.501^{* * *} \\
(1.182- \\
1.905)\end{array}$ \\
\hline
\end{tabular}


Reportable Injury History

\begin{tabular}{lccccc} 
Injury within 2 yrs of retirement & $1.626 * * *$ & $1.614^{* * *}$ & $1.622 * * *$ & $1.618^{* * *}$ & $1.606 * * *$ \\
& $(1.351-$ & $(1.340-$ & $(1.346-$ & $(1.343-$ & $(1.322-$ \\
\hline Observations & $1.957)$ & $1.945)$ & $1.955)$ & $1.951)$ & $1.953)$ \\
Birth Cohort FE & 1667 & 1660 & 1660 & 1660 & 1490 \\
Location FE & YES & YES & YES & YES & YES \\
Tenure FE & YES & YES & YES & YES & YES \\
\hline
\end{tabular}


Table 4: Cox Proportional Hazard Model of years to retirement after reaching age 58 including time-varying eligibility

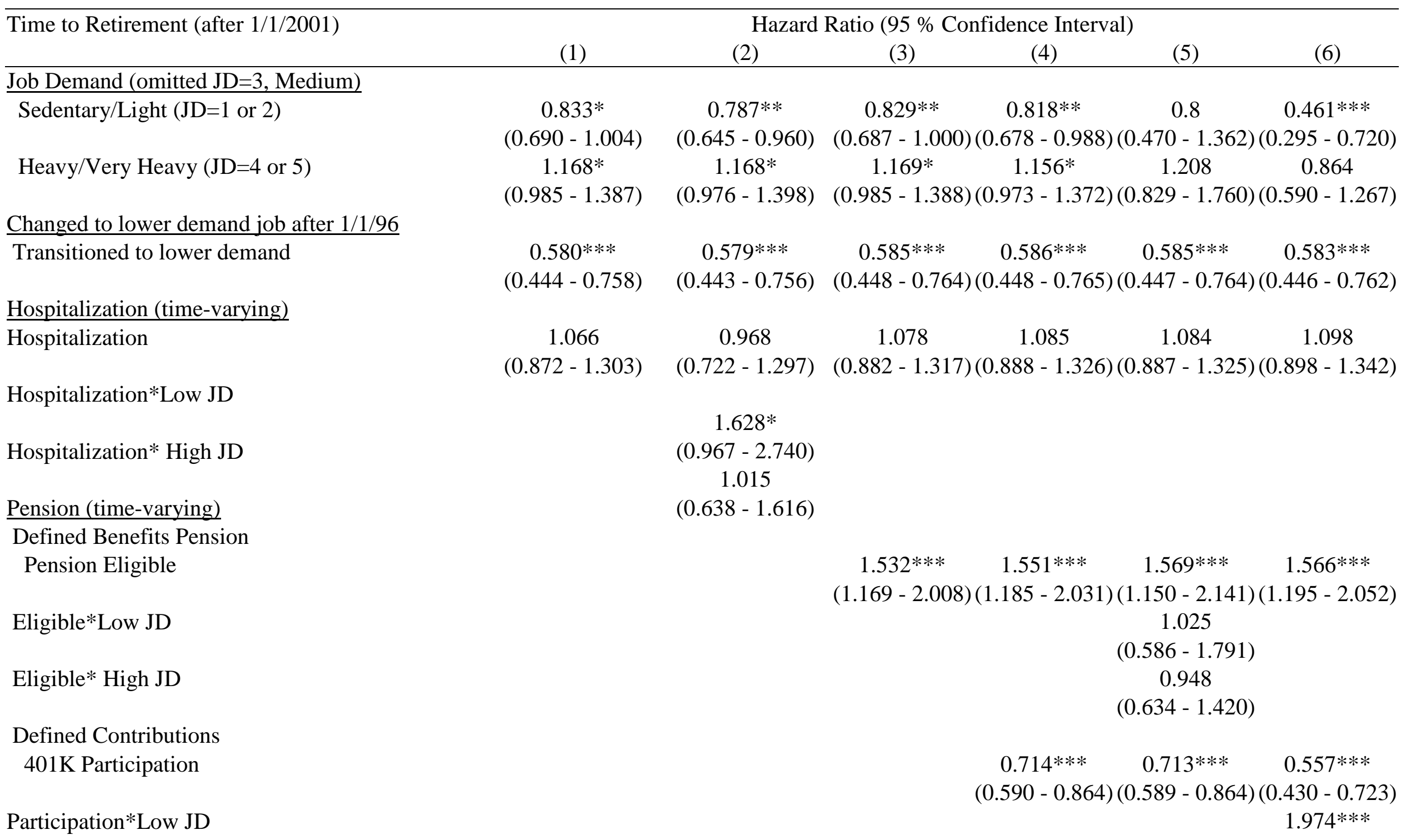




\begin{tabular}{|c|c|c|c|c|c|c|}
\hline Participation* High JD & & & & & & $\begin{array}{c}(1.226-3.181) \\
1.405^{*} \\
(0.942-2.095)\end{array}$ \\
\hline Observations & 5189 & 5189 & 5189 & 5189 & 5189 & 5189 \\
\hline Unique Workers & 1488 & 1488 & 1488 & 1488 & 1488 & 1488 \\
\hline Birth Cohort FE & YES & YES & YES & YES & YES & YES \\
\hline Location FE & YES & YES & YES & YES & YES & YES \\
\hline Tenure FE & YES & YES & YES & YES & YES & YES \\
\hline
\end{tabular}

Controls for final wage, injury history, race, health risk score in 2000, and ever-married 
Table 5: Cox Proportional Hazard Model of years to retirement after reaching age 58 including time-varying pension payouts

\begin{tabular}{|c|c|c|c|c|}
\hline \multirow[t]{2}{*}{ Time to Retirement (after 1/1/2001) } & \multicolumn{4}{|c|}{ Hazard Ratio (95 \% Confidence Interval) } \\
\hline & (1) & (2) & (3) & (4) \\
\hline \multicolumn{5}{|l|}{ Job Demand (omitted JD=3, Medium) } \\
\hline \multirow[t]{2}{*}{ Sedentary/Light (JD=1 or 2$)$} & 0.872 & 0.631 & 0.88 & 0.806 \\
\hline & $\begin{array}{l}(0.713- \\
1.066)\end{array}$ & $\begin{array}{l}(0.182- \\
2.187)\end{array}$ & $\begin{array}{l}(0.719- \\
1.078)\end{array}$ & $\begin{array}{l}(0.592- \\
1.096)\end{array}$ \\
\hline \multirow[t]{2}{*}{ Heavy/Very Heavy (JD=4 or 5) } & 1.077 & 0.591 & $1.221 * *$ & 1.024 \\
\hline & $\begin{array}{c}(0.890- \\
1.303)\end{array}$ & $\begin{array}{c}(0.207- \\
1.686)\end{array}$ & $\begin{array}{c}(1.012- \\
1.473)\end{array}$ & $\begin{array}{c}(0.762- \\
1.375)\end{array}$ \\
\hline \multicolumn{5}{|l|}{ Changed to lower demand job after 1/1/96 } \\
\hline \multirow[t]{2}{*}{ Transitioned to lower demand } & $0.695 * *$ & $0.697 * *$ & $0.568 * * *$ & $0.566 * * *$ \\
\hline & $\begin{array}{c}(0.518- \\
0.932)\end{array}$ & $\begin{array}{c}(0.519- \\
0.936)\end{array}$ & $\begin{array}{c}(0.427- \\
0.756)\end{array}$ & $\begin{array}{c}(0.425- \\
0.753)\end{array}$ \\
\hline \multicolumn{5}{|l|}{ Hospitalization (time-varying) } \\
\hline \multirow[t]{2}{*}{ Hospitalization } & 1.181 & 1.183 & 1.051 & 1.047 \\
\hline & $\begin{array}{c}(0.952- \\
1.464)\end{array}$ & $\begin{array}{c}(0.954- \\
1.467)\end{array}$ & $\begin{array}{c}(0.842- \\
1312)\end{array}$ & $\begin{array}{c}(0.838- \\
1308)\end{array}$ \\
\hline \multicolumn{5}{|l|}{ Pension (time-varying) } \\
\hline \multicolumn{5}{|l|}{ Defined Benefits Pension } \\
\hline \multirow[t]{2}{*}{ Pension Benefits (100\$/month) } & $1.516^{* * *}$ & $1.495 * * *$ & & \\
\hline & $(1.417-$ & $(1.391-$ & & \\
\hline \multirow[t]{3}{*}{ Benefit*Low JD } & & 1.02 & & \\
\hline & & $(0.945-$ & & \\
\hline & & 1.100) & & \\
\hline \multirow[t]{3}{*}{ Benefit* High JD } & & 1.036 & & \\
\hline & & $(0.975-$ & & \\
\hline & & 1.101) & & \\
\hline \multicolumn{5}{|l|}{ Defined Contributions } \\
\hline \multirow{2}{*}{$\begin{array}{l}\text { Annuitized Monthly Values (100\$) (3\% rate of } \\
\text { return for } 25 \text { yrs) }\end{array}$} & & & $1.041 * * *$ & $1.026 *$ \\
\hline & & & (1.018 - & (0.995 - \\
\hline \multirow[t]{3}{*}{ Annuity*Low JD } & & & & 1.018 \\
\hline & & & & $(0.964-$ \\
\hline & & & & $\begin{array}{l}1.075) \\
1.037\end{array}$ \\
\hline \multirow{2}{*}{ Annuity*High JD } & & & & $\begin{aligned} 1.037 \\
(0.990-\end{aligned}$ \\
\hline & & & & $1.086)$ \\
\hline Observations & 3780 & 3780 & 4586 & 4586 \\
\hline Unique Workers & 1211 & 1211 & 1293 & 1293 \\
\hline Birth Cohort FE & YES & YES & YES & YES \\
\hline
\end{tabular}


Location FE

YES

YES

YES

YES

Tenure FE

YES

YES

YES

YES

Controls for final wage, injury history, race, health risk score in 2000, and ever-married 


\section{References}

Blau, D. \& Goldstein, R. 2007. What Explains Trends in Labor Force Participation of Older Men in the United States? Institute for the Study of Labor Discussion Paper. Bonn, Germany.

Blöndal, S. \& Scarpetta, S. 1999. The Retirement Decision in OECD Countries. OECD Economics Department Working Papers [Online]. Available: http://www.oecd.org/dataoecd/36/30/1866098.pdf.

Busch, S. H., Barry, C. L., Vegso, S. J., Sindelar, J. L. \& Cullen, M. R. 2006. Effects of a CostSharing Exemption on Use of Preventive Services at One Large Employer. Health Affairs, 25, 1529-1536.

Cantley, L., Ienacco, J., Slade, M. D., Vegso, S., Taiwo, O., Fiellin, M., Schwartz, Kasl, S. V. \& Cullen, M. 2007. An Externally Rated Job Demand Survey to Assess Physical and Psychological Job Stress in Relation to Injury Risk in Aluminum Manufacturing Jobs.

Clougherty, J. E., Eisen, E. A., Slade, M. D., Kawachi, I. \& Cullen, M. R. 2009. Workplace Status and Risk of Hypertension Among Hourly and Salaried Aluminum Manufacturing Employees. Social Science \&Amp; Medicine, 68, 304-313.

Duncan, G. J. \& Holmlund, B. 1983. Was Adam Smith Right After All? Another Test of the Theory of Compensating Wage Differentials. Journal Of Labor Economics, 1, 366-379.

Elovainio, M., Forma, P., Kivimaki, M., Sinervo, T., Sutinen, R. \& Laine, M. 2005. Job Demands and Job Control as Correlates of Early Retirement Thoughts in Finnish Social and Health Care Employees. Work \& Stress, 19, 84-92.

Finkelstein, A., Einav, L., Pascu, I. \& Cullen, M. 2012. How General Are Risk Preferences? Choices Under Uncertainty in Different Domains. American Economic Review.

Gustman, A. \& Steinmeier, T. 1986. A Structural Retirement Model. Econometrica, 54, 555-584.

Gustman, A. \& Steinmeier, T. 2002. The Social Security Early Entitlement Age in a Structural Model of Retirement and Wealth.

Hayward, M., Grady, W., Hardy, M. \& Sommers, D. 1989. Occupational Influences on Retirement, Disability, and Death. Demography, 26, 393-409.

Hayward, M. D. 1986. The Influence of Occupational Characteristics on Men's Early Retirement. Social Forces, 64, 1032-45.

Hurd, M. \& Mcgarry, K. 1993. The Relationship Between Job Characteristics and Retirement. NBER Working Papers. National Bureau of Economic Research, Inc. 
Iennaco, J., Cullen, M. R., Cantley, L., Slade, M. D., Fiellin, M. \& Kasl, S. V. 2010. Effects of Externally Rated Job Demand and Control on Depression Diagnosis Claims in an Industrial Cohort. American Journal Of Epidemiology, 171, 303-311.

Kubicek, B., Korunka, C., Hoonakker, P. \& Raymo, J. M. 2010. Work and Family Characteristics as Predictors of Early Retirement in Married Men and Women. Research on Aging, 32, 467-498.

Mein, G., Martikainen, P., Stansfeld, S. A., Brunner, E. J., Fuhrer, R. \& Marmot, M. G. 2000. Predictors of Early Retirement in British Civil Servants. Age and Ageing, 29, 529-536.

O'leary, P., Boden, L., Seabury, S., Ozonoff, A. \& Scherer, E. 2012. Workplace Injuries and the Take-up of Social Security Disability Benefits. Social Security Bulletin, 72.

Pollack, K. M., Agnew, J., Slade, M. D., Cantley, L., Taiwo, O., Vegso, S., Sircar, K. \& Cullen, M. R. 2007. Use of Employer Administrative Databases to Identify Systematic Causes of Injury in Aluminum Manufacturing. American Journal of Industrial Medicine, 50, 676686.

Quinn, J. F. 1978. Job Characteristics and Early Retirement. Industrial Relations: A Journal of Economy and Society, 17, 315-323. 


\section{RECENT WORKING PAPERS FROM THE CENTER FOR RETIREMENT RESEARCH AT BOSTON COLLEGE}

Changes in Labor Force Participation of Older Americans and Their Pension Structures: A Policy Perspective

Frank W. Heiland and Zhe Li, July 2012

How Would GASB Proposals Affect State and Local Pension Reporting?

Alicia H. Munnell, Jean-Pierre Aubry, Joshua Hurwitz and Laura Quinby, June 2012

Borrow Less Tomorrow: Behavioral Approaches to Debt Reduction

Dean Karlan and Jonathan Zinman, May 2012

Spousal Labor Market Effects from Government Health Insurance: Evidence from A Veterans Affairs Expansion

Melissa A. Boyle and Joanna N. Lahey, April 2012

Measuring Social Security Proposals by More than Solvency: Impacts on Poverty, Progressivity, Horizontal Equity, and Work Incentives

Melissa M. Favreault and C. Eugene Steuerle, April 2012

How Important Is Asset Allocation to Financial Security in Retirement?

Alicia H. Munnell, Natalia Sergeyevna Orlova, and Anthony Webb, April 2012

Great Recession-Induced Early Claimers: Who Are They? How Much Do They Lose?

Matthew S. Rutledge and Norma B. Coe, April 2012

Effects of Employer Health Costs on the Trend and Distribution of Social Security-Taxable Wages

Gary Burtless And Sveta Milusheva, April 2012

Should Households Base Asset Decumulation Strategies on Required Minimum Distribution Tables?

Wei Sun and Anthony Webb, April 2012

Geographic Mobility Among Residents in Seniors Housing and Care Communities: Evidence from the Residents Financial Survey

Norma B. Coe and April Yanyuan Wu, April 2012

Costs and Concerns among Residents in Seniors Housing and Care Communities: Evidence from the Residents Financial Survey

Norma B. Coe and April Yanyuan Wu, April 2012

All working papers are available on the Center for Retirement Research website (http://crr.bc.edu) and can be requested by e-mail (crr@bc.edu) or phone (617-552-1762). 